\title{
Spectroscopic and Dynamical Studies of Highly Energized Small Polyatomic Molecules
}

\author{
Robert W. Field \\ Co-principal Investigator \\ Robert J. Silbey \\ Co-principal Investigator
}

\section{Department of Chemistry \\ Massachusetts Institute of Technology 77 Massachusetts Avenue Cambridge, Massachusetts 02139}

\section{DISCLAIMER}

This report was prepared as an account of work sponsored by an agency of the United States Government. Neither the United States Gnvernment nor any agency thereof, nor any of their employees, makes any warranty, express or implied, or assumes any legal liability or responsibility for the -uracy, completeness, or usefulness of any information, apparatus, product, or process disclosed, or represents that its use would not infringe privately owned rights. Reference herein to any specific commercial product, process, or service by trade name, trademark, manufacturer, or otherwise does not necessarily constitute or imply its endorsement, recommendation, or favoring by the United States Government or any agency thereof. The views and opinions of authors expressed herein do not necessarily state or reflect those of the United States Government or any agency thereof. 
The formyl radical, in addition to its importance as a combustion intermediate, is emerging as a watershed molecule in Physical Chemistry. Many experiments and theoretical calculations sample global and detailed features of the lowest energy potential surface of $\mathrm{HCO}$ in complementary ways.

We have shown that Richard Dixon's analysis of the hydrocarbon flame bands is essentially correct. The $\widetilde{B}$ and $\widetilde{C}$ states turn out to be a single ${ }^{2} \mathrm{~A}^{\prime}$ state, which at least in its low vibrational and low-J,K levels is sufficiently free of predissociation to provide a basis fc: sensitive LIF monitoring of HCO via the extremely strong, hybrid a, b-polarized $\widetilde{\mathrm{B}}-\tilde{\mathrm{X}}$ system. The $\widetilde{B}-\tilde{X}$ system has a much higher oscillator strength and fluorescence quantum yield than the $\widetilde{\mathrm{A}}-\tilde{\mathrm{X}}$ system. We have completed a detailed rotational analysis and fit of the $\widetilde{\mathrm{B}}-\tilde{\mathrm{X}} \mathrm{O}_{0}^{0}$ band. A comparison of early- and late-gated fluorescence excitation spectra of the $\widetilde{\mathrm{B}}-\tilde{\mathrm{X}} \mathrm{O}_{0}^{0}$ band shows that some high-J,K levels have significantly shorter lifetimes than the low-J,K levels. We plan systematic study of the rotational and vibrational mechanisms of predissociation and collisional quenching in the HCO $\widetilde{B}$-state. The quenching study will show whether the $\widetilde{B}-\tilde{X}$ system really is superior to the $\tilde{\mathrm{A}}-\tilde{\mathrm{X}}$ system at the $>100$ Torr pressures typically relevant for in situ combustion diagnostics.

We have recorded SEP spectra of $\mathrm{HCO}$. These spectra sample vibrational "levels" or "resonances" in the $\widetilde{\mathrm{X}}^{2} \mathrm{~A}^{\prime}$ state at energies well above $\left(\sim 4000 \mathrm{~cm}^{-1}\right)$ the $\mathrm{H}-\mathrm{CO}$ dissociation limit. Our initial results show that the $\left(\mathrm{v}_{\mathrm{CH}}, \mathrm{v}_{\mathrm{CO}}, \mathrm{v}_{\text {bend }}\right)=(0,5,0)$ level has a longer lifetime $(\Gamma$ $\left.=0.8 \mathrm{~cm}^{-1}\right)$ than the lower lying $(0,4,1)$ level $\left(\Gamma=6 \mathrm{~cm}^{-1}\right)$. This mode specificity demonstrates the correctness of $m$ initio predictions of long-lived resonances and the relative effectiveness of $\mathrm{C}-\mathrm{H}$ vs. $\mathrm{C}-\mathrm{O}$ vs. bend vibrations in promoting dissociation. We plan to extend our SEP studies to other vibrational levels of the $\tilde{\mathrm{X}}^{2} \mathrm{~A}^{\prime}$ state, especially those predicted to lie close to the dissociation threshold, and to document the vibrational and rotational dependence of unimolecular dissociation rates.

In order to record SEP spectra of the HCO radical, we had to modify our SEP detection scheme to permit photolytic generation of $\mathrm{HCO}$ (from acetaldehyde) and to suppress spurious signals due to excitation of non- $\mathrm{HCO}$ species (i.e., acetaldehyde, $\mathrm{CH}_{3}, \mathrm{H}_{2} \mathrm{CO}$, etc.) by the DUMP laser. Our photolysis SEP setup should now make it possible for us to record SEP spectra of other photolytically generated species. 
2. Optical-Optical Double Resonance (OODR) Studies of Acetylene.

We have recorded onto diskettes an enormous quantity of SEP spectra of acetylene. In the process of assembling all of these spectra into large and systematic data files, we discovered many unusual features which did not belong to $\widetilde{A}^{1} \mathrm{~A}_{\mathrm{u}}-\widetilde{X}^{1} \Sigma_{\mathrm{g}}+$ SEP spectra of acetylene. Among these are two new predissociated singlet valence states. The $\widetilde{\mathrm{C}}^{\prime 1} \mathrm{~A}_{\mathrm{g}}$ state $\left(\mathrm{T}_{0}=62,300\right.$ $\left.\mathrm{cm}^{-1}\right)$ is planar, strongly trans-bent $\left(\theta_{\mathrm{CCH}}=102^{\circ}\right)$, and formally $C-C$ single-bonded $\left(\pi^{2} \pi^{* 2}\right)$. The $\widetilde{\mathrm{E}}^{1} \mathrm{~B}$ state $\left(\mathrm{T}_{0}=74,613 \mathrm{~cm}^{-1}\right)$ is a non-planar near-trans, $\mathrm{C}=\mathrm{C}$ doubly bonded $\left(\pi^{3} \pi^{*}\right)$ state initially identified by Wilkinson but disputed by virtually all later experimental and theoretical studies. Both of these predissociated states have fully resolvable rotational structure only in OODR spectra of their zero-point vibrational level. Studies of $\mathrm{HCCH}$ and DCCD have enabled us to determine the $\Gamma_{0}$ structures in the $\widetilde{C}^{\prime}$ and $\widetilde{E}$ states. It appears that, owing to the presence of two H's and two C's, group theory (plus OODR spectroscopy) is capable of distinguishing between a wide array of isomeric forms: planar trans, planar cis, planar vinylidene, nonplanar near-trans, nonplanar near-cis, and unequal $\mathrm{C}-\mathrm{H}$ bond lengths.

We also have observed some strong downward transitions, from the DCCD $\tilde{A}^{1} \mathrm{~A}_{u} v_{3}=5$ level, into ribrational levels near $28,000 \mathrm{~cm}^{-1}$. There are many features of these spectra which lead us to believe that these new vibrational levels belong to the cis-acetylene isomer minimum of the lowest triplet surface. SEP transitions from $\mathrm{S}_{1}$ (trans) to $\mathrm{T}_{1}$ (cis) are made allowed by spin-orbit perturbations between $\mathrm{S}_{1}$ (trans) and $\mathrm{T}_{2}$ near the cis-trans (linear) isomerization barrier. This isomerization barrier on $\mathrm{T}_{2}$ is not idle speculation; our Zeeman and Stark anticrossing and quantum beat spectra of $\mathrm{HCCH}$ have located this $\mathrm{T}_{2}$ cis-truns barrier maximum at an energy near $\mathrm{HCCH} \mathrm{S}_{1} \mathrm{v}_{3}=2$ or 3 . We plan systematic study of the cis-bent acetylene and vinylidene isomers on the $T_{1}$ and $T_{2}$ surfaces by "perturbation facilitated" SEP spectroscopy.

\section{Zeeman and Stark Anticrossing (ZAC and SAC) and Quantum Beat (ZQB and SQB) Studies of Acetylene}

The $\mathrm{J}=\mathrm{K}=\mathrm{I}=\mathrm{O}$ levels of $\mathrm{HCCH} \widetilde{\mathrm{A}}^{1} \mathrm{~A}_{\mathrm{u}} \mathrm{v}_{3}=0-3$ can be populated via hot band transitions (out of $\tilde{X}^{1} \Sigma_{g}{ }^{+} v_{4}=1, \ell=1, J=1$ ). These are the simplest possible levels for rionitoring the properties of dark triplet states via ZAC spectroscopy. The density of anticrossings observed as the magnetic field is scanned from 0 to 8 Tesla should be simply related to the density of triplet vibrational levels. The observed rapid increase in $\mathrm{ZAC}$ density from $\mathrm{v}_{3}=0$ to $\mathrm{v}_{3}=3$ forces us to conclude that an unprecedented triplet-facilitated $S_{1} \rightarrow S_{0}$ anticro-sing mechanism is operative. The reason for the abrupt increase in ZAC density is that the top of the planar cis-trans 
isomerization barrier on the $\mathrm{T}_{1}$ or $\mathrm{T}_{2}$ surface must be located at an energy near $\tilde{\mathrm{A}}^{1} \mathrm{~A}_{\mathrm{u}} \mathrm{v}_{3}=2$ or 3 .

$\mathrm{ZQB}, \mathrm{SAC}$, and SQB experiments confirm this interpretation.

These experiments provide an unusually detailed view of both Intersystem Crossing and Internal Conversion in a small polyatomic molecule. They also provide us with numerous points of spectroscopic access to the acetylene and vinylidene triplet manifolds.

4. The Dissociation Energy of Acetylene, $\mathrm{D}_{0}(\mathrm{HCC}-\mathrm{H})$.

When an electric field of $113 \mathrm{kV} / \mathrm{cm}$ is applied to acetylene in the $\widetilde{A}^{1} \mathrm{~A}_{\mathrm{u}} \mathrm{v}_{3}=2$ state, several rotational levels exhibit increases in fluorescence decay rates. Such increases in decay rates are normally conclusive evidence for predissociation. After carefully examining what seemed to us to be all conceivable alternative explanations of this electric field induced lifetime shortening effect, we were led to propose an extremely controversial low value of an upper bound on $D_{0}(\mathrm{HCC}-\mathrm{H}) \leq 126.647 \pm 0.002 \mathrm{kcal} / \mathrm{mol}$. The enormous weight of diverse and elegant experiments and calculations in support of a value for $D_{0}(\mathrm{HCC}-\mathrm{H}) \sim 6 \mathrm{kcal} / \mathrm{mol}$ higher than our value has forced us to reexamine our predissociation interpretation of the electric field induced lifetime shortening effect. The key to our graceful retreat from our probably too-low upper bound is the above-mentioned cis-trans barrier triplet-facilitated $\mathrm{S}_{1} \rightarrow \mathrm{S}_{0}$ interaction. 
Publications since 1985 resulting from DOE sponsorship

E. Abramson, H.-L. Dai, R.W. Field, D.G. Imre, J.L. Kinsey, C. Kittrell, D.E. Reisner, and P.H. Vaccaro, "Laser Population of Highly Excited Vibrational Levels of Molecules," Reactants and Probes in Chemistry, W.M. Jackson and A.B. Harvey, eds. pp. 393-404 Howard University Press, 1985.

E. Abramson, R.W. Field, D. Imre, K.K. Innes, and J.L. Kinsey, "Fluorescence and Stimulated Emission $S_{1} \rightarrow S_{0}$ Spectra of Acetylene: Regular and Ergodic Regions," J. Chem. Phys. $\underline{83}$ 453-465 (1985).

R. L. Sundberg, E. Abramson, J.L. Kinsey, and R.W. Field, "Evidence of Quantum Ergodicity in Stimulated Emission Pumping Spectra of Acetylene", J. Chem. Phys. 83 466-475 (1985).

G.J. Scherer, Y. Chen, R.L. Redington, J.L. Kinsey, and R.W. Field, "An Unsuspected Fermi Perturbation in the Acetylene $\widetilde{A}^{\mathrm{A}_{\mathfrak{u}}} 3 \vee_{3}$ Level", J. Chem. Phys. 85 , 6315-6323 (1986).

C.E. Hamilton, J.L. Kinsey, and R.W. Field, "Stimulated Emission Pumping: New Methods in Spectroscopy and Molecular Dynamics," Ann. Rev. Phys. Chem. 37, 493-524 (1986).

J.P. Pique, Y. Chen, R.W. Field and J.L. Kinsey, "Chaos and Dynamics on 30fs-1ns Time Scales in Vibrationally Excited Acetylene: Fourier Transform of Stimulated Emission. Pumping Spectrum", Phys. Rev. Letts. $\underline{58}$ 475-478 (1987).

R.W. Field, "High Resolution Spectroscopy of Small Molecules", Conference Laser M2P, 1987, J. de Physique C7, 17-28 (1987).

Y. Chen, D.M. Jonas, C.E. Hamilton, P.G. Green, J.L. Kinsey, and R.W. Field, "Acetylene: Isomerization and Dissociation," Berichte der Bunsengesellschaft für Physikalische Chemie, 92 329-336 (1988).

J.-P. Pique, Y. Chen, R.W. Field, and J.L. Kinsey, "Laser Spectroscopy and Quantum Chaos: An Example Through the Fourier T'ransform of a Stimulated Emission Pumping Spectrum of $\mathrm{C}_{2} \mathrm{H}_{2}$ at Very High Vibrational Energy", Conference Laser M2P, 1987, J. de Physique C7 655-657 (1987).

J.P. Pique, Y. Chen, R.W. Field, J.L. Kinsey, and M. Lombardi, "New Order Out of the Chaotic Bath of Highly Excited Vibrational States of $\mathrm{C}_{2} \mathrm{H}_{2}$ ", Berichte der Bunsengesellschaft für Physikalishe Chemie 92, 422-424 (1988).

J.P. Pique, Y.M. Engel, R.D. Levine, Y.Chen, R.W. Field, and J.L. Kinsey, "Broad Spectral Features in the Stimulated Emission Pumping Spectrum of Acetylene", ]. Chem. Phys. $\underline{88}$ 59725974 (1988).

M.H. Alexander, P. Andresen, R. Bacis, R. Bersohn, F.J. Comes, P.J. Dagdigian, R.N. Dixon, R.W. Field, G.W. Flynn, K.-H. Gericke, B.J. Howard, J.P. Huber, D.S. King, J.L. Kinsey, K. Kleinermanns, A.C. Luntz, A.J. MacCaffery, B. Pouilly, H. Reisler, S. Rosenwaks, E. Rothe, M. Shapiro, J.P. Simons, R. Vasudev, J.R. Wiesenfeld, C. Wittig, and R.N. Zare, "A Nomenclature for $\Lambda$ Doublet Levels in Rotating Linear Molecules", J. Chem. Phys. 89 1749-1753 (1988).

R.W. Field, "Pathologically Complex Spectra of Small Molecules: High Resolution Techniques for Displaying Vibrational Chaos and Electronic Simplicity", Conference on Quantum 
'Electronics and Laser Science, 1989 Technical Digest Series, Vol. 12 (Optical Society of America, Washington, DC), pp. 160-162 (Talk THHH2), 1989.

R.W. Field, "Statistical Spectroscopy: Insight or Nonsense?", ILS-IV, 1988, Am. Instit. of Phys. Conf. Proc. 191, 673-682 (1988).

P.G. Green, J.L. Kinsey, and R.W. Field, "A New Determination of the Dissociation Energy of Acetylene", J. Chem. Phys. 91 5160-5163 (1989).

Y. Chen, D.M. Jonas, J.L. Kinsey, and R.W. Field, "High Resolution Spectrosc'opic Detection of Acetylene $\leftrightarrow$ Vinylidene Isomerization by Spectral Cross-Correlation" J. Chem. Phys. 91 39763987 (1989).

J. Vander Auwera, T.R. Huet, M. Herman, C. Hamilton, J.L. Kinsey, and R.W. Field, "The $\tilde{\mathrm{A}}^{1}$ A" Electronic State of Monodeuterated Acetylene", J. Mol. Spectrosc. 137, 3,81-395 (1989).

C.E. Hamilton, R.W. Field, T.R. Huet, and M. Herman, "Low Energy Vibrational Levels in the $\widetilde{A}^{1} \mathrm{~A}_{\mathrm{u}}$ Electronic State of $\mathrm{C}_{2} \mathrm{D}_{2}$ ", J. Mol. Spectrosc. 137, 427-429 (1989).

Y. Chen, S.D. Halle, D.M. Jonas, J.L. Kinsey, and R.W. Field, "Stimulated Emission Pumping Studies of Acetylene $\tilde{X}^{1} \Sigma_{\mathrm{g}}^{+}$in the 11,400-15,700 $\mathrm{cm}^{-1}$ Region: the Onset of Mixing", J. Opt. Soc. Am. B 00 0000-0000 (1990).

X. Zhao, G.W. Adamson, and R.W. Field, "The $\widetilde{B}^{2} \mathrm{~A}^{\prime} \leftarrow \widetilde{\mathrm{X}}^{2} \mathrm{~A}^{\prime}$ Fluorescence Excitation Spectrum of the HCO Radical", J. Chem. Phys.

K. Yamanouchi, N. Ikeda, S. Tsuchiya, D.M. Jonas, J.K. Lundberg, and R.W. Field, "Vibrationally Highly Excited Acetylene as Studied by Dispersed Fluorescence and Stimulated Emission Pumping Spectroscopy: Vibrational Assignment of the Feature States", J. Chem. Phys.

P. Dupré, R. Jost, M. Lombardi, P.G. Green, E. Abramson, and R.W. Field, "Anomalous Behavior of the Anticrossing Density as a Function of Excitation Energy in the $\mathrm{C}_{2} \mathrm{H}_{2}$ Molecule", Chem.

Phys. 

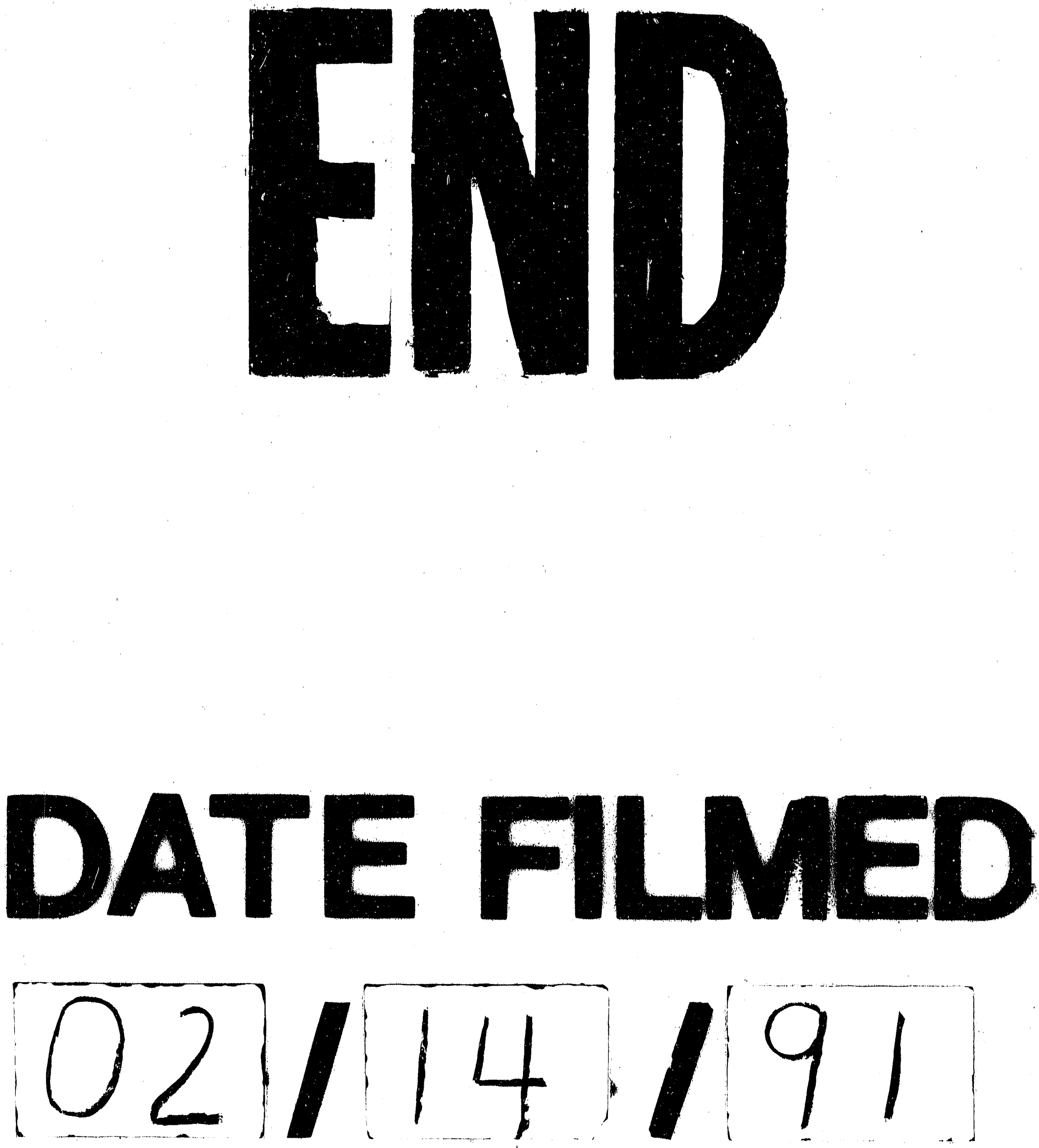
